\title{
Quality Control of a Laser Additive Manufactured Medical Implant by X-Ray Tomography
}

\author{
Anton du Plessis, ${ }^{1,2}$ Stephan Gerhard le Roux, Gerrie Booysen, ${ }^{3}$ and Johan Els ${ }^{3}$
}

\begin{abstract}
Quality control of laser additive manufactured medical implants is of interest, especially if nondestructive quality control can be performed on parts before implantation. X-ray micro-computed tomography (microCT or CT) can be used for defect/porosity analysis as well as for comparing the part surface with its computer-aided design (CAD) file. In both cases, the limited use of CT is partly due to the variation in scan types and the quality of scans that can occur. We present a simple method demonstrating the use of a light metal casting as a reference porosity sample, to confirm good CT image quality and to quantify minimum detectable pore size for the selected CT scan settings. This makes a good comparison for additive manufactured parts, since castings generally contain more porosity. A full part-to-CAD comparison shows how the part is compared with its $\mathrm{CAD}$ file, as a second-quality control. The accuracy of the CAD variance is given by the minimum detectable pore size. Finally, the part is sectioned and scanned at two higher resolution settings showing small porosity (10-50 $\mu \mathrm{m}$ diameter) present but well distributed, as expected.
\end{abstract}

Keywords: X-ray tomography, additive manufacturing, porosity, defect detection, medical implant, quality control

\section{Introduction}

AdDitive MANUFACTURING Is a technology that allows the direct production of complex geometry parts, with time and cost advantages for the manufacture of custom-designed individual products such as custom medical implants. Additive manufacturing of metals is possible through the use of both electron beam melting and laser melting. ${ }^{-3}$

Quality control in metal additive manufacturing is extremely important, both for dimensional accuracy and for minimizing or eliminating defects. Widely used destructive characterization methods include sectioning and optical analysis of metallographic thin sections, as well as scanning electron microscopy and transmission electron microscopy. ${ }^{4}$ Mechanical testing is also used to ensure that good mechanical properties are obtained from individual systems. ${ }^{5-7}$ Such an indirect confirmation of build quality, combined with systemspecific online monitoring such as ensuring the atmosphere is clean, the powder quality is good, the scraper is functioning well, and the laser power is constant, allows high-quality parts to be built. High-quality parts are especially required in additive manufacturing for aerospace parts, ${ }^{8}$ automotive engine parts, ${ }^{9}$ and medical implants. ${ }^{10}$

However, nondestructive testing of critical components is still very useful, as this allows direct testing of the actual part to be used. X-ray computed tomography (CT) scanning of mechanical parts for porosity and defects is widely used and allows the 3D visualization of pores and cracks, provides average and individual pore size information, including information such as pore size distributions, their relation to the surface, and much more. The use of X-ray CT in the materials sciences has been recently reviewed. ${ }^{11} \mathrm{X}$-ray micro-tomography has been applied successfully to the characterization of scaffold structures that are built with metal additive manufacturing. ${ }^{12}$ It has also been used, for example, to produce models for additive manufacturing of unique objects. ${ }^{13}$ The general application of X-ray tomography to additive manufactured parts was reported in a conference paper, ${ }^{14}$ and its application to the

\footnotetext{
${ }^{1}$ CT Scanner Facility, Central Analytical Facilities, Stellenbosch University, Stellenbosch, South Africa.

${ }^{2}$ Physics Department, Stellenbosch University, Stellenbosch, South Africa.

${ }^{3}$ Centre for Rapid Prototyping and Manufacturing, Central University of Technology, Bloemfontein, South Africa.

(C) Anton du Plessis, et al., 2016; Published by Mary Ann Liebert, Inc. This Open Access article is distributed under the terms of the Creative Commons License (http://creativecommons.org/licenses/by/4.0), which permits unrestricted use, distribution, and reproduction in any medium, provided the original work is properly credited.
} 
characterization of additive manufacturing porosity was studied for an electron beam melting system, for small test objects under various build conditions very recently. ${ }^{15}$ A unique type of layered defect in an additive manufactured part, detected by X-ray micro-computed tomography (microCT), was recently reported. ${ }^{16}$ A systematic study of cavities or induced defects by X-ray microCT was also recently reported. ${ }^{17}$ The method has also been applied to the analysis of consumergrade 3D prints. ${ }^{18}$ Similar CT metrology and porosity analyses of additive manufactured parts are presented. ${ }^{19}$ The method has an American Society for Testing and Materials (ASTM) standard for choice of scan parameters and analysis methods. ${ }^{20}$ A recent review of nondestructive testing of additive manufactured components discusses various aspects, including the use of X-ray tomography. ${ }^{21}$

The use of X-ray CT for the quality control of additive manufactured parts is, therefore, not a new concept, but image quality and detail detectability can vary considerably between systems and even between different types of scans on the same system. As an example, a part of $100 \mathrm{~mm}$ and a part of $20 \mathrm{~mm}$ cannot be directly compared, as the best possible resolution is limited by the size of the object, resulting in different defect detection capabilities. The aim of this article is to demonstrate the different types of analysis possible at varying resolution and quality settings on a small medical implant manufactured by laser additive manufacturing under optimized conditions, and in the final state destined for medical use. A light metal casting was used as a direct comparison with the additive component. The casting shows higher porosity and, therefore, acts as an image quality indicator. Besides direct comparison and identification of potential defects (or the lack thereof), the 3D dimensional accuracy is also tested against its design, with the same CT data. This method, therefore, acts as a "standard" for medical implant analysis, including discussion of the important requirements for good CT image quality. Finally, high-resolution scans are done of offcut sections, indicating that the majority of the porosity is very small (10$50 \mu \mathrm{m})$ and well distributed in the part.

\section{Experimental Details}

$\mathrm{X}$-ray microCT scans were performed at the Stellenbosch University CT Scanner Facility, using in this case both a General Electric Nanotom $\mathrm{S}$ and a General Electric Phoenix V|Tome|X L240. Most scans reported here were done with $150 \mathrm{kV}$ and up to $220 \mu \mathrm{A}$, with $500 \mathrm{~ms}$ per image and scans up to 60 min excluding setup and post-processing time. In this study, the scans with voxel sizes $25-100 \mu \mathrm{m}$ were done with the V|TomeX L240 system; the scans with voxel sizes 5-1.4 $\mu \mathrm{m}$ were done with the Nanotom $\mathrm{S}$ system.

Analysis was performed in Volume Graphics VGStudioMax 2.2. Porosity analysis was performed using standard segmentation methods, making use of advanced surface determination tools, region selections, and porosity analysis using the custom defect mask method. This method allows the user control over the analysis process, to ensure no faulty assignments are made.

The AlSi casting sample was provided by Prof Irfan of Qassim University and has been the subject of investigation in another CT analysis publication. ${ }^{22}$ The medical implant was provided by CUT and was built on an EOS M280 direct metal laser sintering machine using a Ti64 performance $30 \mu \mathrm{m}$ parameter set. The implant was manufactured from a biocompatible Ti6Al4V (ELI) powder of sub-40 $\mu \mathrm{m}$ particle size. The sample is a nasal cavity implant: A similar implant has since been successfully implanted in a patient.

\section{Results and Discussion}

\section{Variation of scan resolution}

A series of scans were conducted at varying resolution and quality settings to demonstrate the effect on porosity visualization. In this work, three scans were conducted with both a light metal casting and the additive manufactured medical implant, in the same scan. The combination of two or more parts in the same scan allows for a direct comparison between the two samples, ensuring that the image quality and detail detectability are identical.

These scans vary from $100 \mu \mathrm{m}$ (total field of view $\sim 150 \mathrm{~mm}$ ) up to $25 \mu \mathrm{m}$ (total field of view $\sim 35-40 \mathrm{~mm}$ ). The better the resolution, the smaller the detected defects; however, the field of view becomes smaller. Individual scans of the casting and additive part were done by using higher quality by increasing the averaging and number of acquired images.

Figure 1 clearly shows how higher resolution and quality allows smaller defects to be detected. In particular, the largest pore in the casting is detected in all scans but it is clearer with sharper edges in the higher quality images; whereas total porosity detected increases as the resolution improves. Since the casting and additive parts are scanned together, it is clear that the additive part has much less porosity than the casting. However, scanning of parts together reduces image quality, sometimes causing dark lines or streaks across the image. This can negatively affect the ability for image processing, which can result in a failed porosity analysis in extreme cases.

It is clear that various scans can provide various types of information. The $100 \mu \mathrm{m}$ scan is very fast ( $15 \mathrm{~min}$ ) and provides a good quality indication, ensuring that no major defects are present in the additive part; whereas the higher the resolution, the better the potential information provided from the scan. Quantitative information of all these scans is shown in Table 1. These values are 3D pore diameters that must be interpreted with care. It must be considered that usual metallography in 2D underestimated pore sizes due to the sectioning process, as studied in Nicoletto et al..$^{23}$ Therefore, the pore diameters seem larger than usual for the metallurgical engineer.

Besides resolution and image quality, the scanning of parts individually ensures the highest possible quality. This must be weighed against the requirement for image quality indicators, whereby a light metal casting is shown to be useful for this purpose. It must be mentioned that for materials with a significantly different X-ray density, the method will not work well, as this will shift the material absorptions and limit the contrast of each type of material and its ability to detect defects. Therefore, ideally the same material, or one of a very similar density as is demonstrated here, must be used for reference.

In Table 1, it is clear that as the scan resolution improves from 100 to $50 \mu \mathrm{m}$ to $25 \mu \mathrm{m}$, the total number of detected pores increases in the casting sample; although this is also true for the additive sample, no defects are detected at 100 or $50 \mu \mathrm{m}$ for this sample. As the resolution improves, the smallest detected pore diameter also becomes smaller, indicating the ability to detect smaller pores. The largest pore size remains essentially constant, whereas its accuracy is improved as the resolution improves, due to a better discrimination of the edge, and, 

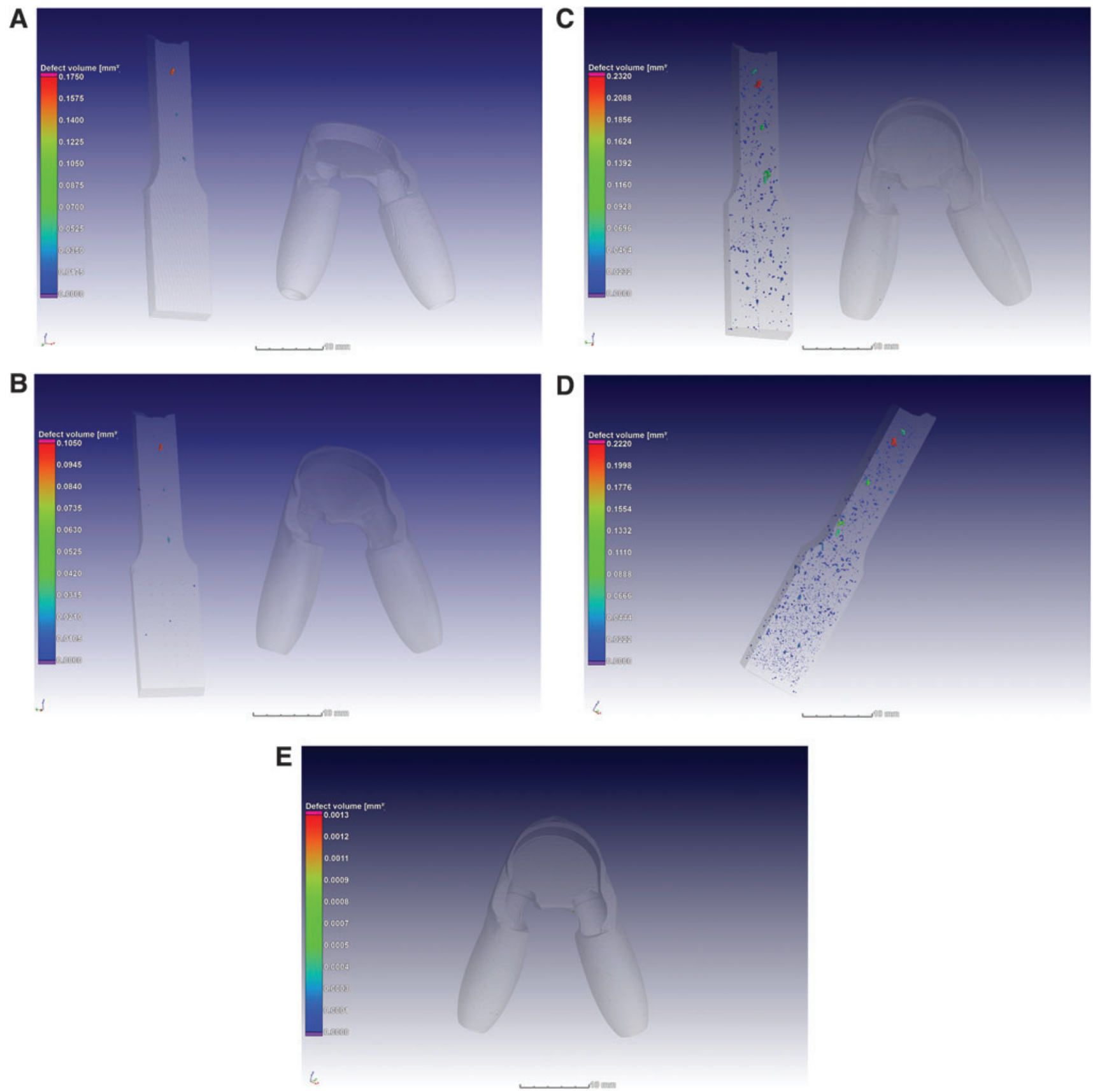

FIG. 1. 3D porosity analysis at varying resolution and quality (A) $100 \mu \mathrm{m}$, (B) $50 \mu \mathrm{m}$, (C) $25 \mu \mathrm{m}$, (D) $25 \mu \mathrm{m}$ high-quality casting alone, and (E) $25 \mu \mathrm{m}$ high-quality additive part alone. Color images available online at www.liebertpub.com/3dp

Table 1. Statistical Porosity Analysis of the Parts from the Different Scans in Figure 1

\begin{tabular}{lccccc}
\hline Part & $\begin{array}{c}\text { Scan } \\
\text { resolution }(\mu \mathrm{m})\end{array}$ & $\begin{array}{c}\text { Number of } \\
\text { detected defects }\end{array}$ & $\begin{array}{c}\text { Average } \\
\text { porosity } \%\end{array}$ & $\begin{array}{c}\text { Largest diameter } \\
\text { pore }(\mu \mathrm{m})\end{array}$ & $\begin{array}{c}\text { Smallest detected } \\
\text { pore }(\mu \mathrm{m})\end{array}$ \\
\hline Casting & 100 & 4 & 0.027 & 1060 & 460 \\
Additive & 100 & 0 & 0 & - & - \\
Casting & 50 & 9 & 0.016 & 1020 & -18 \\
Additive & 50 & 0 & 0 & 1470 & 79 \\
Casting & 25 & 584 & 0.1905 & 270 & 85 \\
Additive & 25 & 34 & 0.00067 & 1420 & 61 \\
Casting alone & 25 & 2624 & 0.287 & 260 & 85 \\
Additive alone & 25 & 37 & 0.00075 & \\
\hline
\end{tabular}

Detailed porosity analysis of the cast metal type reported here can be found in Ref. ${ }^{22}$ 
hence, improves volumetric measurement. The average porosity generally increases in this case due to the difference in the amount of pores detected at varying resolution settings, with a slight decrease between 100 and $50 \mu \mathrm{m}$ for the casting, contrary to what is expected. This can be explained by the largest pore, which is measured too large at $100 \mu \mathrm{m}$ resolution, causing an average porosity value that is higher than expected in this case. Generally, when analyzing the individual scans compared with the combined scans at $25 \mu \mathrm{m}$, the individual scans resolve more pores, show a higher average porosity due to the larger number of pores and slightly smaller pores are detected in the casting; whereas in the additive part, the minimum pore size is the same (due to the relatively small number of pores present).

\section{Computer-aided design variance}

Besides nondestructive testing for potential defects, the actual dimensional accuracy is also important. X-ray CT allows surface determination, which can be better than the scan resolution, and produces a very high density of surface data for a comparison to computer-aided design (CAD) data. Since voxel data allow the material edge to be determined based on relative gray values in the $3 \mathrm{D}$ data grid, it is possible to obtain the material surface location at a precision better than the voxel size uncertainty, by interpolation between gray values (i.e., sub-voxel). The detailed description is not within the scope of this article, but the precision of the obtained surface data can be up to $10 \%$ of the voxel size under ideal conditions, but will in most cases be at least better than the voxel size, which was $25 \mu \mathrm{m}$ in this case. The implant was manufactured on support structures, as shown in Figure 2, and the accuracy of the part can be influenced where these structures are attached. The use of CT for dimensional metrology, its calibration and the quantification of the $10 \%$ voxel size precision, can be found in more detail in. ${ }^{24-27}$

A part-to-CAD comparison is shown in Figure 3 and Supplementary Video S1 (Supplementary Data are available online at www.liebertpub.com/3dp). A CAD variance can be calculated for each surface element by calculating the distance to the nearest CAD file surface element, and it can be color-coded according to the variance value of that surface element. This is also shown in Figure 3, with the largest variance shown in red on the one side of the part, where the supports were removed. This is expected for as-built parts.

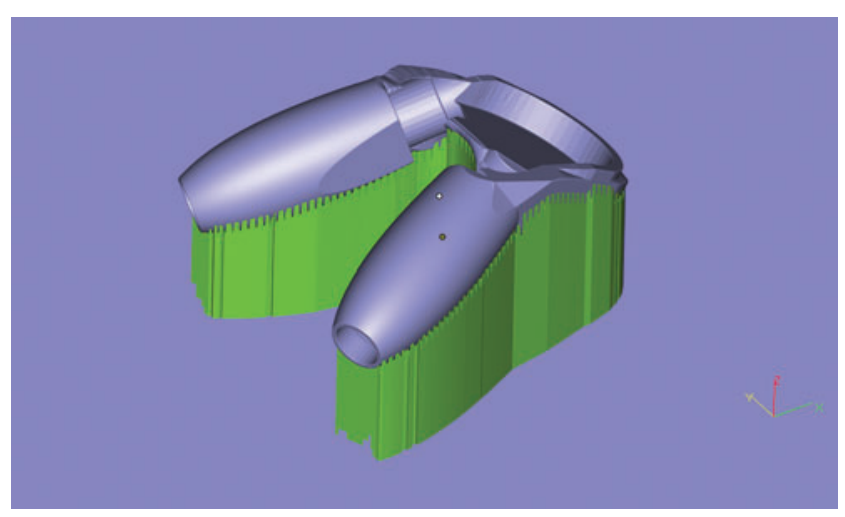

FIG. 2. DMLS implant manufactured on support structures. DMLS, direct metal laser sintering. Color images available online at www.liebertpub.com/3dp
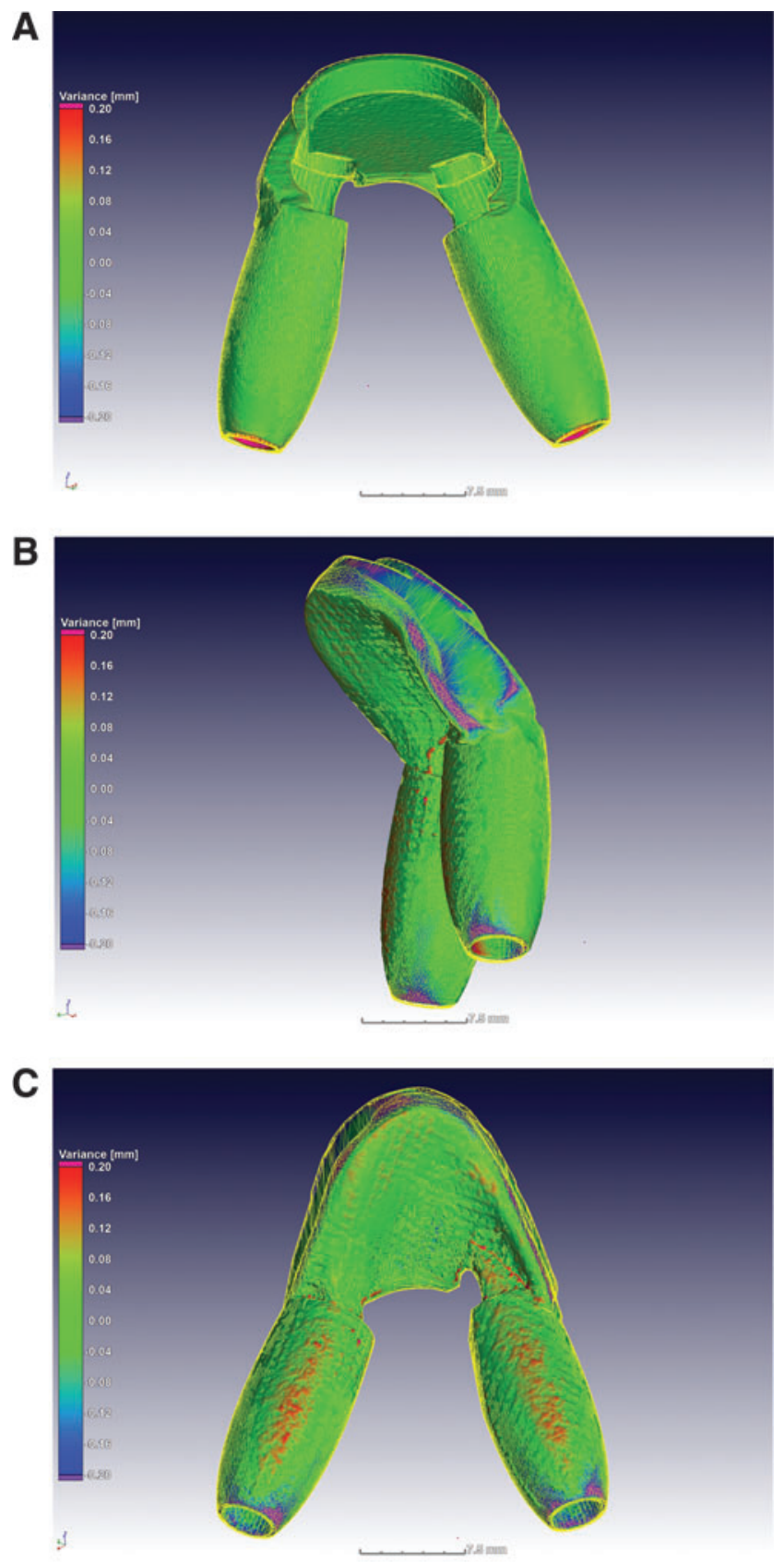

FIG. 3. (A), (B) and (C) show different viewing angles from front, side, and back, respectively. Part-to-CAD comparison showing the CAD design file in yellow wire mesh, and the actual part with overlay variance in color. Green areas indicate very little variance. A video is available as Supplementary Data. CAD, computer-aided design. Color images available online at www.liebertpub.com/3dp

The maximum variance is seen to be $\sim 0.2 \mathrm{~mm}$, which is significantly more than the smallest detectable pore size in this scan setting, that is, $0.06 \mathrm{~mm}$. In this case, the $90 \% \mathrm{cu}-$ mulated variance value is $0.099 \mathrm{~mm}$, which means that $90 \%$ of the variance is smaller than $99 \mu \mathrm{m}$.

\section{Microporosity}

Even though nondestructive 3D analysis is ideal, samples can be sectioned and scanned at a higher resolution as would 
make sense to understand the medical implant porosity that is not clearly resolved at a resolution of $25 \mu \mathrm{m}$. To better understand the porosity at a higher resolution, a $3 \mathrm{~mm}$ section of the bottom right of the sample in Figure 3 (c) was sectioned using a wire cutter. This section was chosen to be a representative of the bulk and, subsequently, scanned at two high-resolution settings: (1) $5 \mu \mathrm{m}$ resolution covering the entire offcut section and (2) a further higher resolution scan $(1.4 \mu \mathrm{m})$ covering only one section of the field of view $\sim 2 \mathrm{~mm}$, chosen on the "support-side" to investigate the area of the highest porosity. The results are shown next in Figures 4 and 5 and Supplementary Videos S2 and S3. The pores are more clearly viewed and are homogeneously distributed, which is good for the structural integrity of the part.

Slightly larger pores are found on the "support build" side of the part. This is an interesting result but it must be kept in mind that these are extremely small pores $(10-50 \mu \mathrm{m}$ in this case), again considering the underestimation of $2 \mathrm{D}$ metallography compared with $3 \mathrm{D}$ metallography. ${ }^{23}$ A possible explanation could be the intersection of the support structures into the implant surface (as shown in Fig. 6) and after support removal, this could result in some small pores (10-50 $\mu \mathrm{m}$ in this case) that are close to the surface. The intersecting height of the supports is $0.06 \mathrm{~mm}$, and the crosssectional size of the contact surface between the teeth and the part is $0.3 \times 0.1 \mathrm{~mm}$.

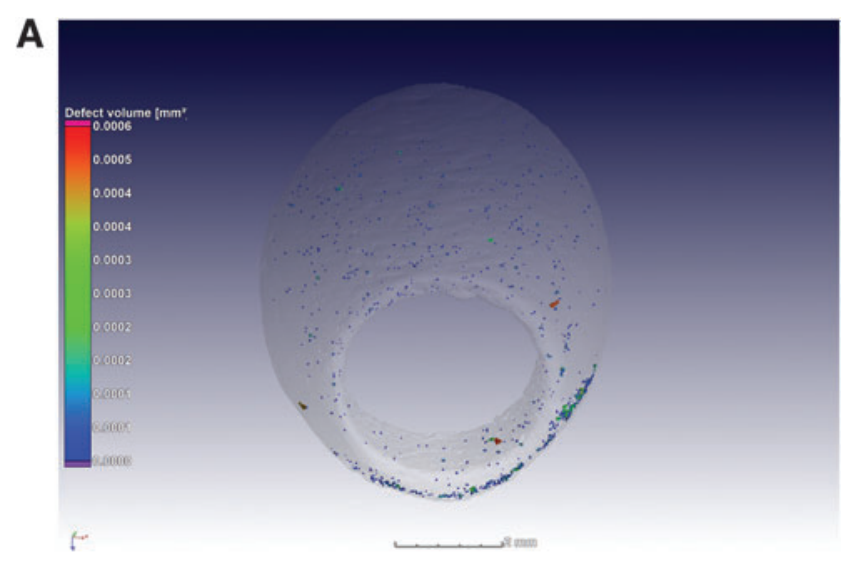

B

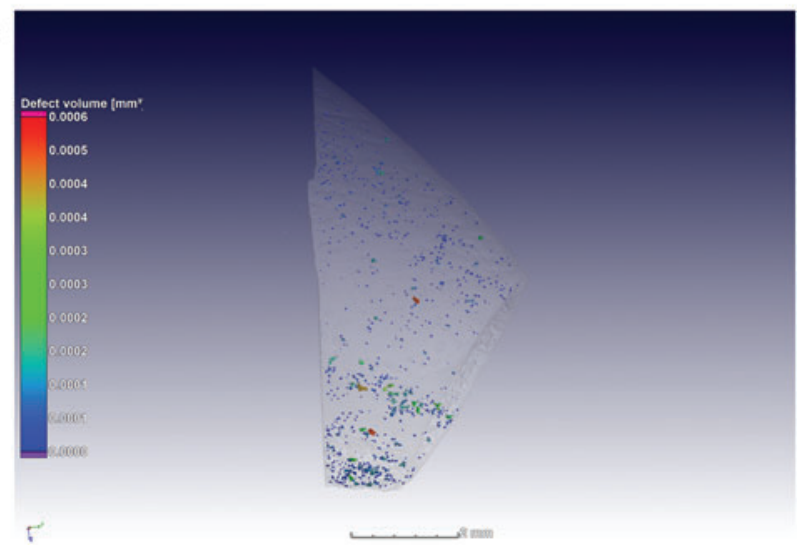

FIG. 4. High-resolution scan $(5 \mu \mathrm{m})$ of an offcut section of the same medical implant with a field of view of $5 \mathrm{~mm}$, showing larger porosity on the support side (bottom of image). $3 \mathrm{D}$ images are shown at (A) zero and (B) $90^{\circ}$ orientations. Video available as Supplementary Data. Color images available online at www.liebertpub.com/3dp

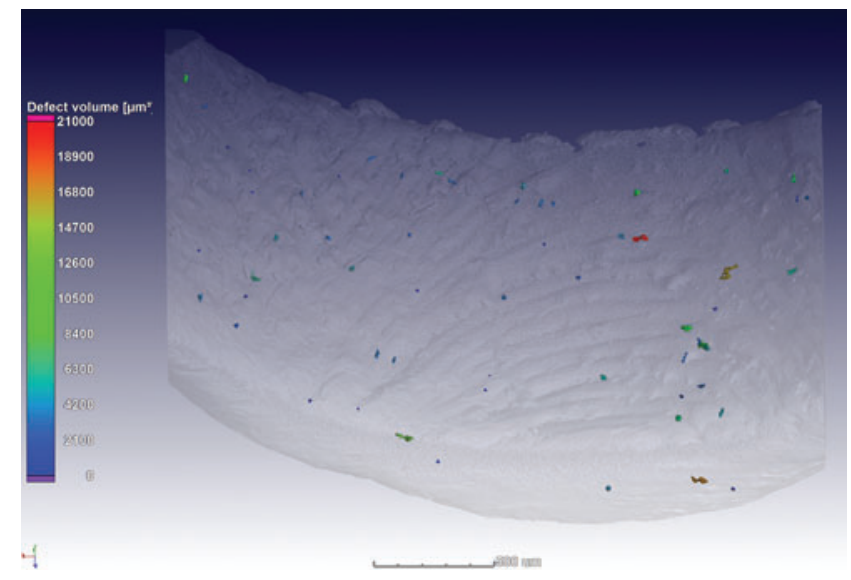

FIG. 5. High-resolution region of interest scan $(1.4 \mu \mathrm{m})$ of a region on the support side of the offcut section with a field of view of $2 \mathrm{~mm}$. Video available as Supplementary Data. Color images available online at www.liebertpub.com/3dp

Pore statistics from these scans are presented in Table 2, analogous to Table 1 showing the range of pore sizes detected (the smallest and largest detected pores), the number of detected pores in the field of view, the average porosity, and the average pore diameter. Again, it must be emphasized that these values are true $3 \mathrm{D}$ pore diameters at their widest points, which are not directly comparable with sectioned 2D pore diameters. ${ }^{23}$

The results of Table 2 and Figure 7 indicate that at $5 \mu \mathrm{m}$ with a field of view of $\sim 5 \mathrm{~mm}$, the diameter of the smallest detected pore is $18 \mu \mathrm{m}$ and the average pore diameter is $60 \mu \mathrm{m}$. Since the smallest pore detected is chosen to be at least $3 \times 3 \times 3$ voxels in the analysis step, the expected minimum detectable pore diameter is consistent with this diameter value ( $15 \mu \mathrm{m}$ for an ideal cube). At a higher resolution of $1.4 \mu \mathrm{m}$ with a field of view of $\sim 2 \mathrm{~mm}$, the smallest detected pore is found to be $10 \mu \mathrm{m}$, whereas its expected minimum detectable pore size would be $4.2 \mu \mathrm{m}$ for an ideal cube. This indicates a lack of pores in the range $4-10 \mu \mathrm{m}$, which is an interesting result. Since the ability to detect pores in this range might be questioned, as it reaches the limit of the system capabilities, a similar scan was done on the AlSi casting and pores in the range $4-10 \mu \mathrm{m}$ were positively identified as shown in Figure 8 in 3D and slice images, with a $4.7 \mu \mathrm{m}$ diameter pore as example.

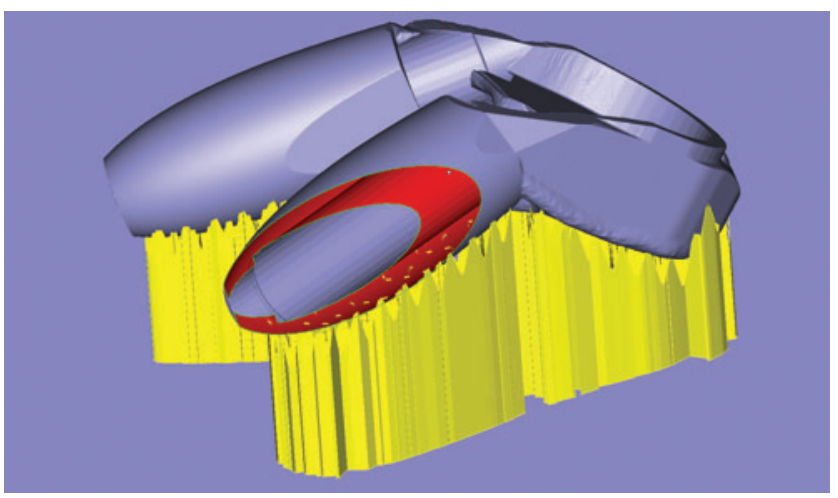

FIG. 6. Intersection of the support structures into the implant surface. Color images available online at www .liebertpub.com/3dp 
Table 2. Microporosity Results from High-Resolution Scans of Offcut Sections

\begin{tabular}{lcccccc}
\hline Part & $\begin{array}{c}\text { Scan resolution } \\
(\mu \mathrm{m})\end{array}$ & $\begin{array}{c}\text { Number of } \\
\text { detected defects }\end{array}$ & $\begin{array}{c}\text { Average } \\
\text { porosity\% }\end{array}$ & $\begin{array}{c}\text { Largest diameter } \\
\text { pore }(\mu \mathrm{m})\end{array}$ & $\begin{array}{c}\text { Smallest detected } \\
\text { pore }(\mu \mathrm{m})\end{array}$ & $\begin{array}{c}\text { Average pore } \\
\text { diameter }(\mu \mathrm{m})\end{array}$ \\
\hline Offcut & 5 & 776 & 0.054 & 240 & 18 & 60 \\
Offcut ROI section & 1.4 & 59 & 0.0067 & 105 & 10 & 37 \\
\hline
\end{tabular}

ROI, region of interest.

The difference in average porosity, which shows a higher average porosity for the entire offcut, can be explained by the fact that the largest pore is found in a region that is not in the support area where the highest resolution scan was done, which affects the average porosity measurement. However, a statistical analysis shows the pore size distribution peak at 40 and $50 \mu \mathrm{m}$ for the two scans, as shown in Figure 7.

The interesting result here is that the smallest detected pores are $>10 \mu \mathrm{m}$ in diameter, whereas pores as small as $4 \mu \mathrm{m}$ diameter are easily detectable at $1.4 \mu \mathrm{m}$ resolution. An example of a typical porosity analysis with pores smaller than the scan resolution shows a peak of porosity on the smallest pore size interval, ${ }^{28}$ which is not observed here (the peak is at $40-50 \mu \mathrm{m}$ in this case). It should be noted that pores smaller than $4 \mu \mathrm{m}$ diameter that are not resolvable due to the resolution limit could exist, but it is expected that such pores would not contribute to the functionality of the part.

The pore size distribution peak at $40-50 \mu \mathrm{m}$ formed in this process is of interest and could be a general result for this manufacturing process under this particular system's
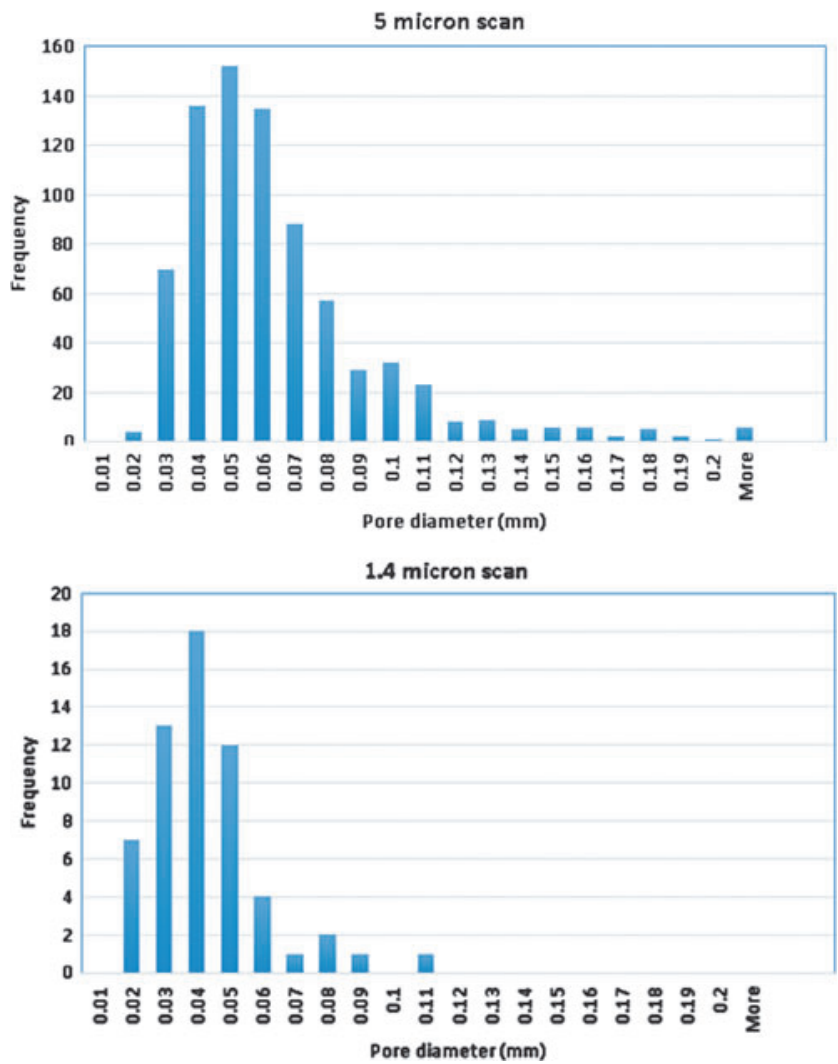

FIG. 7. Pore size distribution statistics showing the peak of pore sizes in the region of $40-50 \mu \mathrm{m}$. Color images available online at www.liebertpub.com/3dp
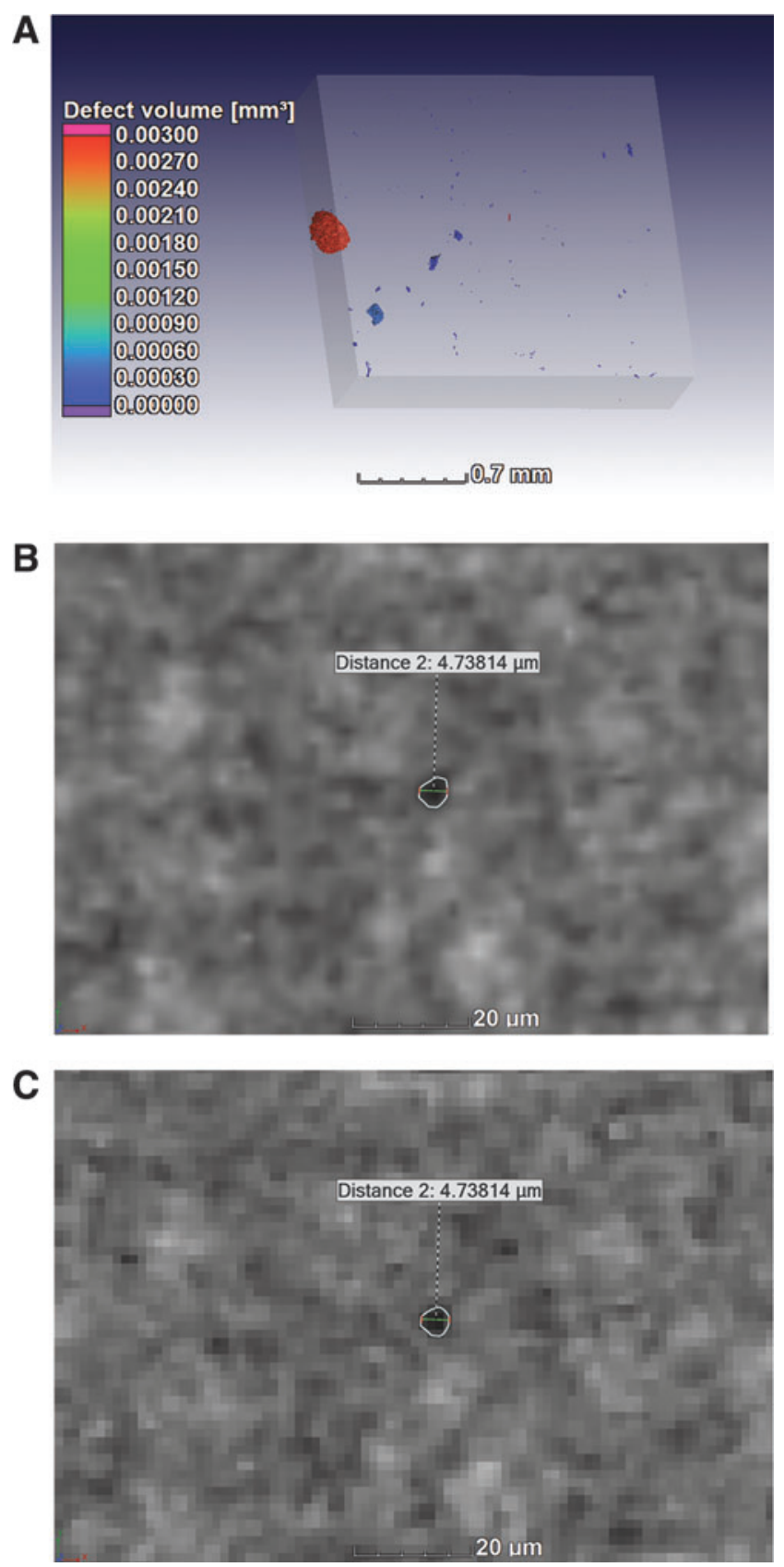

FIG. 8. (A) Defect analysis 3D view of AlSi casting at $1.4 \mu \mathrm{m}$ voxel size, (B) slice image of smallest detected pore diameter of $4.7 \mu \mathrm{m}$ using typical interpolated view, and (C) slice image of the same pore without interpolation. The white line indicates the segmented edge of the pore. Color images available online at www.liebertpub.com/3dp 
"standard" settings. We can speculate that this pore size could be determined by the powder particle size (peak at $20 \mu \mathrm{m})$ in combination with the layer thickness of $30 \mu \mathrm{m}$. A more detailed study with careful parameter variation would assist in understanding this behavior.

\section{Conclusion}

A method for nondestructive quality control of an additive manufactured medical implant was presented, including the use of a casting as a porosity reference in the same scan. A high-quality scan with statistical porosity information was presented; a part-to-CAD variance analysis was demonstrated; and higher resolution scans were demonstrated, indicating the majority of pores in the range of $10-60 \mu \mathrm{m}$ diameter, depending on the region analyzed. These highresolution scans indicate two interesting results: a higher porosity on the support structure side of the sample; a lack of pores in the range of 4-10 $\mu \mathrm{m}$ diameter, allowing an accurate average pore size analysis (detectable pores at the highest resolution would have been able to discriminate pores down to $4 \mu \mathrm{m}$ diameter). The method described can be used to inspect additive manufactured medical implants for major porosity and compared with $\mathrm{CAD}$ data as a standard quality control process. It is envisaged that for quality inspections of these type of parts, a reference porous casting sample is scanned with the part of interest as an image quality indicator, followed by an even higher quality scan without the reference, thereby producing a more complete quality inspection.

\section{Author Disclosure Statement}

No competing financial interests exist.

\section{References}

1. Lawrence E. Murr, Sara M. Gaytan, Diana A. Ramirez, Edwin Martinez, Jennifer Hernandez, Krista N. Amato, et al. Wicker, metal fabrication by additive manufacturing using laser and electron beam melting technologies. J Mater Sci Technol 2012;28:1-14.

2. Frazier WE. Metal additive manufacturing: A review. J Mater Eng Perform 2014;23:1917-1928.

3. Gu DD, Meiners W, Wissenbach K, Poprawe R. Laser additive manufacturing of metallic components: Materials, processes and mechanisms. Int Mater Rev 2012;57:133164.

4. Safdar A, Wei LY, Snis A, Lai Z. Evaluation of microstructural development in electron beam melted Ti-6Al-4V. Mater Charact 2012;65:8-15.

5. Baufeld B, Van der Biest $O$, Gault R. Additive manufacturing of Ti-6Al-4V components by shaped metal deposition: Microstructure and mechanical properties. Mater Des 2010;31:S106-S111.

6. Vrancken B, Thijs L, Kruth JP, Van Humbeeck J. Heat treatment of Ti6Al4V produced by Selective Laser Melting: Microstructure and mechanical properties. J Alloys Compd 2012;541:177-185.

7. Cain V, Thijs L, Van Humbeeck J, Van Hooreweder B, Knutsen R. Crack propagation and fracture toughness of Ti6Al4V alloy produced by selective laser melting. Addit Manuf 2015;5:68-76.

8. Rawal S, Brantley J, Karabudak N. (2013, June). Additive manufacturing of Ti-6Al-4V alloy components for space- craft applications. In Recent Advances in Space Technologies (RAST), 2013 6th International Conference; Istanbul. (pp. 5-11). IEEE. http://ieeexplore.ieee.org/xpl/login.jsp?tp= \&arnumber $=6581260 \& u r l=\mathrm{http} \% 3 \mathrm{~A} \% 2 \mathrm{~F} \% 2 \mathrm{Fieeexplore}$. ieee .org\%2Fxpls\%2Fabs_all.jsp\%3Farnumber\%3D6581260

9. Cooper DE, Stanford M, Kibble KA, Gibbons GJ. Additive manufacturing for product improvement at Red Bull Technology. Mater Des 2012;41:226-230.

10. Vandenbroucke B, Kruth JP. Selective laser melting of biocompatible metals for rapid manufacturing of medical parts. Rapid Prototyp J 2007;13:196-203.

11. Maire E, Withers PJ. Quantitative X-ray tomography. Int Mater Rev 2014;59.1:1-43.

12. Van Bael S, Kerckhofs G, Moesen M, Pyka G, Schrooten J, Kruth JP. Micro-CT-based improvement of geometrical and mechanical controllability of selective laser melted Ti6Al4V porous structures. Mater Sci Eng, 2011; 528: 7423-7431.

13. Du Plessis A, Slabbert R, Swanepoel LC, Els J, Booysen GJ, Ikram S, et al. Three-dimensional model of an ancient Egyptian falcon mummy skeleton. Rapid Prototyp J 2015; 21:368-372.

14. du Plessis A, Seifert T, Booysen G, Els J. Microfocus X-ray computed tomography (CT) analysis of laser sintered parts. S Afr J Ind Eng 2014;25:39-49.

15. Tammas-Williams S, Zhao H, Léonard F, Derguti F, Todd I, Prangnell PB. XCT analysis of the influence of melt strategies on defect population in Ti-6Al-4V components manufactured by Selective Electron Beam Melting. Mater Charact 2015;102:47-61.

16. du Plessis A, le Roux SG, Els J, Booysen G. Application of microCT to the non-destructive testing of an additive manufactured titanium component. Case Studies in Nondestructive Testing and Evaluation 2015;4:1-7.

17. du Plessis A, le Roux SG, Els J, Booysen G. Directionality of cavities and porosity formation in powder-bed laser additive manufacturing of metal components investigated using X-ray tomography. 3D Print Addit Manuf 2016;3:4855.

18. du Plessis A, le Roux SG, Steyn F. X-Ray Computed Tomography of Consumer-Grade 3D-Printed Parts. 3D Print Addit Manuf. 2015;2:190-195.

19. Villarraga H. Assessing additive manufacturing processes with X-ray CT metrology. Proceedings-Aspe 2015 Spring Topical Meeting: Achieving Precision Tolerances in Additive Manufacturing. 2015.

20. ASTM E1570-11. Standard Practice for Computed Tomographic (CT) Examination. ASTM International, West Conshohocken, PA, 2011, www.astm.org

21. Sharratt BM. Non-Destructive Techniques and Technologies for Qualification of Additive Manufactured Parts and Processes. (2015).

22. Al Mufadi FA, Irfan MA. Frequency analysis of volumetric porosity in aluminum castings at high and low cooling rates. Mater Test 2015;57:398-401.

23. Nicoletto G, Anzelotti G, Konečná R. X-ray computed tomography vs. metallography for pore sizing and fatigue of cast Al-alloys. Procedia Engineering 2010;2:547-554.

24. Villarraga H, Morse EP, Hocken R, Smith ST. Dimensional Metrology of Internal Features with X-ray Computed Tomography. American Society for Precision Engineering, ASPE, Boston, 2014.

25. Villarraga H, Lee C, Charney SP, Tarbutton JA, Smith ST. Dimensional Metrology of Complex Inner Geometries 
Built by Additive Manufacturing. American Society for Precision Engineering, ASPE, Raleigh, 2015.

26. Léonard F, Brown SB, Withers PJ, Mummery PM, McCarthy MB. A new method of performance verification for $x$-ray computed tomography measurements. Measurement Science and Technology 2014;25:065401.

27. Jiménez R, Ontiveros S, Carmignato S, Yagüe-Fabra JA. Fundamental correction strategies for accuracy improvement of dimensional measurements obtained from a conventional micro-CT cone beam machine. CIRP Journal of Manufacturing Science and Technology 2013;6:143-148.

28. du Plessis A, Olawuyi BJ, Boshoff WP, le Roux SG. Simple and fast porosity analysis of concrete using X-ray computed tomography. Materials and Structures 2014; $1-10$.

Address correspondence to: Anton du Plessis CT Scanner Facility

Central Analytical Facilities Stellenbosch University

Stellenbosch 7602 South Africa

E-mail: anton2@sun.ac.za 